\title{
EFEITO DO ESTRESSE HÍDRICO SOBRE A EFICIÊNCIA DO HALOSULFURON NO CONTROLE DE TIRIRICA ${ }^{1}$
}

\author{
RICARdo A. MACHADO ${ }^{2}$, AUGUSTO G. F. COST A ${ }^{2}$, PEDRO LUÍS C. A. ALVES ${ }^{3}$ e IBENE T. KAWAGUCHI ${ }^{4}$
}

\section{RESUMO}

Foi conduzido um trabalho em casa de vegetação com o objetivo de estudar o efeito de 10 dias de estresse hídrico ( $\Psi \mathrm{w}$ de $\geq 2,6 ;-2,2 ;-0,35$ e $-0,2 \mathrm{MPa})$ sobre a eficiência do halosulfuron (150g p.c./ha+Aterbane- $0,25 \%$ v/v) no controle de tiririca em pós-emergência. A aplicação do halosulfuron em plantas de tiririca sob estresse de até $-2,6 \mathrm{MPa}$ controlou satisfatoriamente a tiririca desde que irrigadas até 24 horas após a aplicação, mas quando a irrigação ocorreu 48 horas após, houve comprometimento na translocação do herbicida nas plantas. Quando o estresse foi menor que $-2,0 \mathrm{MPa}$, o herbicida manteve-se eficaz no controle de tiririca, principalmente para aquelas com $\Psi_{\mathrm{w}}$ de $-0,35$ $\mathrm{MPa}$.

Palavras chave: Cyperus rotundus, sulfoniluréias, água.

\section{ABSTRACT \\ Effect of water stress on halosulfuron efficacy in the control of purple nutsedge}

A grennhouse experiment was carried out to evaluate the effect of 10 days water stress $\left(\Psi_{\mathrm{w}}\right.$ values of $\geq 2.6 ;-2.2-0.35$, and $-0.2 \mathrm{MPa}$ ) on the efficacy of pos-emergent application of halosulfuron ( $150 \mathrm{~g}$ c.p./ha+Aterbane $0.25 \% \mathrm{v} / \mathrm{v}$ ) in the control of purple nutsedge. When the suitable water supplying began in a period of 24 hours after the herbicide spraying, halosulfuron gave an excellent control of purple nutsedge under every water stress conditions. When the suitable irrigation conditions began 48 hours after herbicide spraying, there was a lower halosulfuron efficacy. When the stress was lower than $-2.0 \mathrm{MPa}$, the herbicide gave a good control, mainly in the $\Psi \mathrm{w}$ of $-0.35 \mathrm{MPa}$. Key words: Cyperus rotundus, sulfonylureas, water.

\section{INTRODUÇÃO}

Dentre as plantas infestantes de culturas agrícolas, a nível mundial, Holm et. al. (1977) incluem a tiririca (Cyperus rotundus) como uma das mais importantes. A tiririca possui uma série de características morfológicas, fisiológicas e de hábito de crescimento que lhe conferem vantagens ecológicas e que dificultam seu controle pelos métodos convencionais. Apresenta uma estratégia de reprodução bastante eficiente, atingindo, em condições ambientais propícias, uma multiplicação intensa e rápida, a razão de 1:10 tubérculos em apenas 60 dias de desenvolvimento do primeiro tubérculo (Magalhães, 1965).

Basicamente, o vegetal consiste de partes aéreas (manifestações epígeas) formada por um conjunto de folhas dispostas em roseta. Suas inflorescências são centrais, do tipo umbela. Possui um complexo sistema subterrâneo que

\footnotetext{
${ }^{1}$ Recebido para publicação em 24/02/99 e na forma revisada em 20/07/2000

2 Acadêmicos de agronomia e estagiários de DBAA/FCAVJ-UNESP

${ }^{3}$ Eng $^{\circ}$ Agr $^{\circ}$, Dr., Professor Assistente Doutor do DBAA/FCAVJ-UNESP. Rod. Carlos Tonnani, Km 5, CEP: 14870-000, Jaboticabal/SP. E-mail: plalves@fcav.unesp.br.

${ }^{4}$ Eng $^{\circ} \mathrm{Agr}^{\circ}$, Bolsista de aperfeiçoamento do DBAA/FCAVJ-UNESP.
} 
compreende raízes, tubérculos e bulbos basais, interligados por rizomas (Hazard \& Palu, 1986). Os tubérculos, de acordo com citação de Stoller \& Sweet (1987), atuam como as principais unidades de dispersão, permanecendo dormentes no solo por longos períodos. Estes brotam quando as condições são apropriadas, produzindo novas plantas que perpetuam a infestação. A diferenciação dos rizomas nas plantas de tiririca é influenciada por fatores do ambiente, tais como; fotoperíodo, temperatura, umidade e características do solo.

Com referência à situações ambientais específicas, especialmente aquelas que conferem estresse à espécie, vários estudos têm evidenciado que a tiririca muda seu padrão de alocação de recursos, ora incrementando o esforço reprodutivo, ora o vegetativo. Alguns autores, como Nemoto et al. (1994, 1995), Erasmo et al. (1994) e Kuva et al. (1995 a,b), têm se dedicado ao estudo dos efeitos ambientais sobre a estratégia reprodutiva desta espécie, tentando encontrar as fases de maior pré-disposição a medidas de controle conhecidas. A viabilidade de tubérculos da tiririca é influenciada sensivelmente pelas condições de umidade do ambiente, no qual permanecem antes do plantio. Quando submetidos a $90 \%$ de umidade relativa do ar, os tubérculos apresentam uma razoável capacidade de brotação após mais de 90 dias de exposição ao sol (Magalhães, 1965).

A umidade do solo pode ser expressa em relação a sua massa ou pela sua capacidade de campo, mas esses não indicam necessariamente a disponibilidade de água para a planta. O potencial de água na planta demonstra essa disponibilidade e é preferencialmente expresso em Pascals (Pa), antigamente Bars (Levitt, 1980).

No caso da tiririca, seguindo a imposição do estresse hídrico, o crescimento e a divisão celular são inibidos e, consequentemente, todo o crescimento da planta é reduzido. Um aumento na deficiência hídrica resulta no fechamento gradual dos estômatos e eventualmente numa rápida queda da fotossíntese, acompanhada por um declínio gradual na respiração e eventual murchamento.
Concomitantemente, ocorrem mudanças no nível de reguladores de crescimento endógenos, enzimas e alterações nas características das membranas e cutícula, resultando em plantas menores com morfologia alterada (Moosavi-nia \& Dore, 1979; Casaley \& Coupland, 1985). De um modo geral, um estresse hídrico prolongado pode levar a um aumento na espessura e densidade da cutícula e da pubescência e, consequentemente, reduzindo a penetração, translocação e metabolismo de herbicidas. Uma breve exposição ao estresse hídrico, isto é, até o murchamento da planta, torna a cutícula menos permeável a água do que era antes e aumenta o ângulo de contato da gota pulverizada com a folha, reduzindo sua molhabilidade.

A umidade do solo pode condicionar direta ou indiretamente a eficiência de um herbicida. No caso de herbicidas de aplicação em pós-emergência das plantas daninhas, o conteúdo de água no solo influencia o estado hídrico das plantas, conforme relatado anteriormente, e o microclima ao redor dessas, condicionando a absorção e translocação de herbicidas. Rahman \& James (1991) verificaram que quando a umidade do solo foi reduzida para $55 \%$ da capacidade de campo, no momento da pulverização, houve diminuição na eficiência das nove sulfoniluréias estudadas para o controle de Sinapsis alba. Esses autores constataram que o efeito do estresse hídrico foi relativamente independente da dose empregada, efeito esse atribuído à redução da translocação dos herbicidas, levando-os a concluir que é necessária uma umidade adequada do solo, no momento da aplicação, para se obter a máxima eficiência de herbicidas do grupo das sulfoniluréias. Resultados semelhantes foram obtidos por Hay (1976) com 2,4-D, por Walia \& Gill (1985) com uréias substituídas e por Harvey \& Crothers (1988) e Zhang \& Price (1993) para glyphosate.

O halosulfuron é um herbicida pertencente ao grupo químico das sulfoniluréias, com ação predominantemente de pós-emergência, sistêmico e recomendado para o controle de tiririca $(C$. rotundus) na cultura da cana-de-açúcar (Rodrigues 
\& Almeida, 1998). Contudo, até o presente momento, não foi encontrada nenhuma publicação específica sobre o efeito do estresse hídrico na eficiência agronômica do halosulfuron, mas apenas a recomendação do fabricante de não aplicá-lo em tiririca sujeita ao estresse hídrico, tal qual é feita para outros herbicidas pós emergentes sistêmicos. Em virtude disso, o presente trabalho teve como objetivo verificar e quantificar o efeito do estresse hídrico sobre a eficiência desse herbicida no controle de tiririca em pósemergência.

\section{MATERIAL E MÉTODOS}

O presente experimento foi conduzido em condições de casa-de-vegetação, pertencente ao Departamento de Biologia Aplicada à Agropecuária (DBAA) da Faculdade de Ciências Agrárias e Veterinárias - UNESP - Campus de Jaboticabal, SP.

Como substrato utilizou-se uma mistura de três partes de um solo coletado na camada arável de um Latossolo Vermelho Escuro, distrófico, A moderado, textura média, peneirado em tamis de 5 mm de abertura, para uma parte de areia de rio lavada. Esse Latossolo apresentava, originalmente, 350 g. $\mathrm{kg}^{-1}$ de argila, $40 \mathrm{~g} \cdot \mathrm{kg}^{-1} \mathrm{de}$ silte e 610 g. $\mathrm{kg}^{-1}$ de areia, sendo, portanto, de textura média.

O substrato foi acondicionado em 64 vasos plásticos com capacidade para 2 litros, nos quais foram plantados quatro tubérculos/vaso. Os tubérculos de tiririca (Cyperus rotundus L.) foram coletados nas imediações do DBAA. Posteriormente, os tubérculos foram lavados e selecionados quanto ao tamanho (comprimento médio de $2 \mathrm{~cm}$ ) e turgidez. Cerca de 25 dias após o plantio dos tubérculos, quando as plantas encontravam-se em pleno estágio vegetativo, foi imposto o estresse hídrico por meio de diferentes níveis de capacidade de saturação do solo.

Os tratamentos constaram de 4 níveis de capacidade de saturação do substrato $(30,45,60$ e próximo a $100 \% \mathrm{p} / \mathrm{p}$ ), de forma a induzir diferentes níveis de estresse hídrico nas plantas de tiririca, sendo estas plantas submetidas ou não a aplicação do halosulfuron (150 g p.c./ha + espalhante adesivo a $0,25 \% \mathrm{v} / \mathrm{v})$. Para melhor entendimento, os tratamentos experimentais estão relacionados na Tabela 1.

TABELA 1. Descrição dos tratamentos experimentais utilizados. Jaboticabal, SP.

\begin{tabular}{cc}
\hline Produto & Capacidade de saturação do solo (\%) \\
\hline & 30 \\
Halosulfuron* (150 g p.c./ha + espalhante adesivo** $^{*}$ & 45 \\
a $0,25 \%$ v/v) & 60 \\
& 100 \\
\hline & 30 \\
Testemunha & 45 \\
& 60 \\
\hline
\end{tabular}

* Sempra; ** Aterbane.

Os diferentes níveis de capacidade de saturação do substrato foram controlados e mantidos durante 10 dias após a obtenção do estágio vegetativo desejado (emissão de seis folhas), com acompanhamento diário para reposição de água com o auxílio do aparelho
Instamatic Duo, cuja escala foi correlacionada com a Capacidade de Saturação (CS) em termos de porcentagem de massa de água presente na massa do substrato.

Ao final do período de imposição do estresse, foi medido o potencial hídrico de duas 
plantas de tiririca por tratamento, utilizando-se, para tanto, uma bomba de Scholander com boa precisão até -2,5MPa Nesta mesma ocasião, ou seja, 35 dias após o plantio dos tubérculos, quando as plantas se encontravam no início do florescimento, foi realizada a aplicação do halosulfuron nos tratamentos específicos. Vinte e quatro horas após a aplicação do produto, foi feita nova medição do potencial hídrico das plantas de tiririca. Para tanto, as partes aéreas das plantas foram cortadas rente a superfície do substrato e inseridas na bomba de Scholander. Em seguida, metade das repetições de cada tratamento voltaram a ser umedecidas normalmente. Mesmo procedimento foi adotado 48 horas após a aplicação para a metade restante das repetições (4 vasos/tratamento). A partir dos cortes da parte aérea até o término do período experimental, aos 28 dias após a aplicação (DAA), os substratos foram umedecidos normalmente, procurando manter a umidade desses em $60 \%$ da C.S.

Os cortes às 24 e 48 horas após a aplicação do produto foram realizados com o intuito de estudar o efeito do estresse hídrico na absorção e translocação do herbicida.

A aplicação do produto na dose de 150 g p.c./ha foi realizada utilizando-se um pulverizador costal mantido à pressão constante $\left(\mathrm{CO}_{2}\right)$, munido de barra com 2 bicos XR $110.02 \mathrm{e}$ regulado para um gasto de volume de calda de 250 1/ha. Por ocasião da aplicação, a umidade relativa do ar era de $77 \%$ e sua temperatura era de $26^{\circ} \mathrm{C}$, enquanto 24 e 48 horas após essas eram de $76 \%$ e $26^{\circ} \mathrm{C}$ e $85 \%$ e $25^{\circ} \mathrm{C}$, respectivamente

$\mathrm{O}$ delineamento experimental utilizado foi o inteiramente casualizado, com 4 repetições por tratamento para cada época de corte da parte aérea. Os tratamentos experimentais foram dispostos em esquema fatorial $4 \times 2$, onde os fatores principais foram os 4 níveis de capacidade de saturação do substrato e as duas condições de aplicação (com e sem), sendo que as parcelas experimentais corresponderam aos vasos plásticos. Os dados obtidos foram submetidos à análise de variância pelo teste $\mathrm{F}$ e as médias comparadas pelo teste de Tukey ao nível de 5\% de probabilidade.

Aos 7, 21 e 28 dias após o corte (DAC) das manifestações epígeas, foram realizadas avaliações quanto ao número de brotações e altura média dessas. Ao final do período experimental, aos $28 \mathrm{DAC}$, as plantas da tiririca foram separadas em tubérculos+raíz e parte aérea, e essas foram ensacadas separadamente e postas para secar em estufa com circulação forçada a $70-80^{\circ} \mathrm{C}$, para determinação da massa da matéria seca.

\section{RESULTADOS E DISCUSSÃO}

Verificou-se que para as capacidades de saturação do substrato de 30 e $45 \%$ os potenciais hídricos das plantas de tiririca foram, em média, de -2,37 e -2,02 MPa, respectivamente, no período de 0 a 48 horas após a aplicação do halosulfuron (Tabela 2). Para as capacidades de saturação de 60 e $100 \%$, os potenciais hídricos foram de $-0,36$ e 0,33 MPa. A partir desses dados, observou-se que uma vez imposto o estresse hídrico nas plantas de tiririca ( 30 e $45 \%$ da C.S.), essas se mantiveram estressadas até 48 após a aplicação do produto, demonstrando que a pulverização não alterou o estado hídrico das plantas, o que pode provavelmente dificultar a absorção e/ou translocação do halosulfuron na planta e, consequentemente, resultar em menor fitointoxicação.

Segundo Winter (1976) um solo argiloso atinge o ponto de murchamento permanente de uma planta quando sua umidade está abaixo de $28 \%$; para um solo arenoso esse ponto cai para $4 \%$. Contudo, as espécies de plantas respondem diferentemente ao ponto de murchamento permanente; o girassol atinge esse ponto quando o potencial hídrico $\left(\psi_{\mathrm{w}}\right)$ varia de $-0,5$ a $-1,8 \mathrm{MPa}$ e o milho o atinge na faixa de $-1,4$ a $-2,6 \mathrm{MPa}$. No presente trabalho pôde-se observar que as plantas de tiririca que foram submetidas a $\psi_{\mathrm{w}}$ de até $-2,6$ MPa não entraram em ponto de murchamento permanente. 
TABELA 2. Potencial hídrico $\left(\psi_{\mathrm{w}}\right)$ nas plantas de tiririca submetidas a diferentes capacidades de saturação (C.S.) do substrato. Medidas realizadas no dia da aplicação (0 h), 24 e 48 horas após. Jaboticabal/SP.

\begin{tabular}{cccc}
\hline \multirow{2}{*}{ C.S. $(\% \mathrm{p} / \mathrm{p})$} & $0 \mathrm{~h}$ & $\psi_{\mathrm{w}}(\mathrm{MPa})$ \\
\cline { 2 - 4 } & $\geq 2,60$ & $24 \mathrm{~h}$ & $48 \mathrm{~h}$ \\
\hline 30 & $-2,20$ & $\geq 2,50$ & $-2,00$ \\
45 & $-0,35$ & $-1,95$ & $-1,92$ \\
60 & $-0,20$ & $-0,32$ & $-0,42$ \\
100 & $-0,40$ & $-0,38$ \\
\hline
\end{tabular}

\section{Corte 24 horas após a aplicação}

Na Tabela 3 encontram-se os resultados de altura, número e massa da matéria seca das brotações e tubérculos de tiririca referentes as plantas cortadas 24 horas após a aplicação. Foi observado, durante todo o período experimental (28 DAC), que não houve alteração na altura das brotações de tiririca quando se comparou os tratamentos submetidos aos diferentes níveis de capacidade de saturação (CS), independentemente da aplicação ou não do herbicida. Entretanto, foi verificada tendência das brotações das plantas de tiririca submetidas a $30 \%$ da CS se apresentarem 20,0\%, em média, maiores do que as brotações de tiririca submetidas à condição de $100 \%$ da CS, demonstrando que o estresse hídrico imposto à planta não comprometeu o vigor dos tubérculos. Resultados semelhantes foram relatados por Winter (1976) para beterraba.

Não foi observado efeito dos níveis de CS sobre o número de brotações por tubérculos até o término do período experimental. Contudo, foi verificada tendência de maior brotação dos tubérculos quando esses foram submetidos aos níveis de 45 e $100 \%$ da CS (Tabela 3). Magalhães (1965) relatou que tubérculos com 35 e $25 \%$ de umidade apresentaram maiores porcentagens de brotação a medida que aumentou a água disponível no solo. Contudo, o autor constatou que com 55\% de umidade nos tubérculos, as maiores porcentagens de brotação ocorreram com apenas $50 \%$ de umidade disponível no solo.

No final do experimento, não foi observado efeito do estresse hídrico na massa da matéria seca dos tubérculos e da parte aérea das plantas de tiririca. Contudo, para a capacidade de saturação do solo de $45 \%$, obteve-se tendência de maior massa de matéria seca dos tubérculos e da parte aérea, quando comparada a das plantas submetidas aos demais níveis de capacidade de saturação do solo (Tabela 3).

Com relação ao efeito do herbicida, foi verificado que a aplicação desse influiu em todos as características analisadas, independentemente do diferentes níveis de capacidade de saturação aos quais as plantas de tiririca foram submetidas. Analisando-se a altura e o número de brotações de tiririca nas diferentes épocas de avaliação, observou-se que a aplicação do halosulfuron na dose de $150 \mathrm{~g}$ p.c./ha proporcionou reduções de 85 e 33\% respectivamente. Aos 28 dias após o corte, foi constatado que a aplicação do halosulfuron, reduziu a massa da matéria seca dos tubérculos e da parte aérea em 45 e $96 \%$, respectivamente (Tabela 3).

Para e sta época de corte, 24 horas após a aplicação, não foi observada interação significativa entre os fatores nível de capacidade de saturação do solo e herbicida para as características analisadas (Tabela 3 ). 
TABELA 3. Altura e número de brotações e massa da matéria seca de tubérculos e da parte aérea de tiririca, quando submetida a diferentes níveis de capacidade de saturação do solo e a aplicação ou não de halosulfuron. Jaboticabal, SP (corte 24 h após a aplicação).

\begin{tabular}{|c|c|c|c|c|c|c|c|c|}
\hline \multirow{2}{*}{$\begin{array}{c}\text { Capacidade de } \\
\text { Saturação do solo }\end{array}$} & \multicolumn{3}{|c|}{ Altura das brotações $(\mathrm{cm})$} & \multicolumn{3}{|c|}{ Número de brotações ${ }^{1 \cdot}$} & \multicolumn{2}{|c|}{ Matéria seca $(\mathrm{g})$} \\
\hline & $7 \mathrm{DAC}^{3}$ & $21 \mathrm{DAC}$ & $28 \mathrm{DAC}$ & $7 \mathrm{DAC}$ & $21 \mathrm{DAC}$ & $28 \mathrm{DAC}$ & Tubérculos & Parte aérea \\
\hline 30 & $4,00 \mathrm{~A}^{2}$ & $5,91 \mathrm{~A}$ & $6,41 \mathrm{~A}$ & $2,50 \mathrm{~A}$ & $2,31 \mathrm{~A}$ & $2,31 \mathrm{~A}$ & $1,82 \mathrm{~A}$ & $0,32 \mathrm{~A}$ \\
\hline 45 & $3,50 \mathrm{~A}$ & $5,50 \mathrm{~A}$ & $5,91 \mathrm{~A}$ & $2,84 \mathrm{~A}$ & $2,72 \mathrm{~A}$ & $2,62 \mathrm{~A}$ & $2,66 \mathrm{~A}$ & $0,59 \mathrm{~A}$ \\
\hline 60 & $3,00 \mathrm{~A}$ & $4,75 \mathrm{~A}$ & $5,16 \mathrm{~A}$ & $2,44 \mathrm{~A}$ & $2,12 \mathrm{~A}$ & $2,31 \mathrm{~A}$ & $1,96 \mathrm{~A}$ & $0,29 \mathrm{~A}$ \\
\hline 100 & $3,30 \mathrm{~A}$ & $4,66 \mathrm{~A}$ & $5,08 \mathrm{~A}$ & $2,82 \mathrm{~A}$ & $2,57 \mathrm{~A}$ & $2,64 \mathrm{~A}$ & $1,86 \mathrm{~A}$ & $0,41 \mathrm{~A}$ \\
\hline \multicolumn{9}{|l|}{ Herbicida } \\
\hline $\mathrm{COM}$ & $1,15 \mathrm{~B}$ & $1,20 \mathrm{~B}$ & $1,33 \mathrm{~B}$ & $2,50 \mathrm{~B}$ & $1,76 \mathrm{~B}$ & $1,81 \mathrm{~B}$ & $1,47 \mathrm{~B}$ & $0,03 \mathrm{~B}$ \\
\hline SEM & $5,75 \mathrm{~A}$ & $9,20 \mathrm{~A}$ & $9,95 \mathrm{~A}$ & $2,80 \mathrm{~A}$ & $3,10 \mathrm{~A}$ & $3,14 \mathrm{~A}$ & $2,68 \mathrm{~A}$ & $0,77 \mathrm{~A}$ \\
\hline F cap. sat.(C) & $1,13 \mathrm{NS}$ & $1,67 \mathrm{NS}$ & $1,42 \mathrm{NS}$ & $2,47 \mathrm{NS}$ & $1,52 \mathrm{NS}$ & $0,81 \mathrm{NS}$ & $2,76 \mathrm{NS}$ & $1,13 \mathrm{NS}$ \\
\hline F herb. $(\mathrm{H})$ & $136,08 * *$ & $294,91 * *$ & $261,27 * *$ & $4,88^{*}$ & $37,78^{* *}$ & $41,63^{* *}$ & $26,35^{* * *}$ & $33,69^{* *}$ \\
\hline $\mathrm{C} \times \mathrm{H}$ & $0,47 \mathrm{NS}$ & $2,58 \mathrm{NS}$ & $1,42 \mathrm{NS}$ & $1,38 \mathrm{NS}$ & $1,04 \mathrm{NS}$ & $0,77 \mathrm{NS}$ & $0,86 \mathrm{NS}$ & $0,59 \mathrm{NS}$ \\
\hline $\mathrm{CV}(\%)$ & 27,99 & 21,90 & 23,15 & 12,33 & 21,88 & 20,38 & 27,84 & 76,40 \\
\hline $\operatorname{DMS}(\mathrm{C})$ & 1,59 & 1,88 & 2,16 & 0,54 & 0,88 & 0,83 & 0,95 & 0,51 \\
\hline DMS (H) & 0,83 & 0,98 & 1,13 & 0,28 & 0,46 & 0,43 & 0,50 & 0,26 \\
\hline
\end{tabular}

${ }^{1}$ Dados transformados para $\sqrt{ }\left(\mathrm{n}^{\mathrm{o}}\right)$

${ }^{2}$ Médias seguidas por mesma letra não diferem entre si a $5 \%$ de probabilidade pelo teste de Tukey

${ }^{3} \mathrm{DAC}=$ dias após o corte da parte aérea 


\section{Corte 48 horas após a aplicação}

Na Tabela 4 encontram-se os resultados das análises das características referentes ao corte da parte aérea da tiririca 48 horas após a aplicação do halosulfuron. Nessa, pode-se observar que houve interação significativa entre os efeitos da capacidade de saturação do solo com a aplicação do herbicida sobre a altura das brotações aos 7 e 28 dias após o corte (DAC), número de brotações dos 7 aos 28 DAC e massa da matéria seca da parte aérea aos 28 DAC.

Para a altura das brotações aos 21 DAC não se verificou efeito significativo da interação entre os fatores, apenas efeito isolado desses. Não houve efeito significativo da C.S., independentemente da aplicação do herbicida, mas observou-se tendência de que os tubérculos submetidos a $30 \%$ da C.S. emitissem brotações mais altas do que os dos demais níveis de saturação. $\mathrm{O}$ halosulfuron, independentemente da C.S., reduziu em $88 \%$ a altura das brotações (Tabela 4). Os níveis de capacidade de saturação, independentemente da aplicação do herbicida, não influenciaram na massa da matéria seca dos tubérculos. Contudo, a aplicação do halosulfuron a reduziu em $50 \%$, independentemente do efeito da C.S.

$\mathrm{Na}$ Tabela 5 pode-se verificar o efeito da interação entre os fatores sobre os parâmetros analisados. A aplicação do halosulfuron reduziu a altura das brotações de tiririca em todos os níveis de saturação do solo, mas esse efeito foi mais acentuado quando o solo encontrava-se com $60 \%$ da C.S. quando comparado ao solo com $30 \%$ da C.S.

Com relação ao número de brotações por tubérculo, foi verificada que a aplicação do halosulfuron só o reduziu quando o solo se encontrava com mais de $30 \%$ da C.S. Aos 7 DAC esse efeito foi mais pronunciado quando o solo estava com $100 \%$ da C.S., mas, a partir dos 21 DAC, esse efeito foi mais acentuado no solo com
$60 \%$ da C.S., no qual não havia mais tubérculos brotados.

O halosulfuron reduziu a massa da matéria seca da parte aérea das plantas de tiririca que se desenvolveram no solo com capacidade de saturação já a partir de 30\%, não havendo diferença no efeito entre os níveis de saturação. $\mathrm{O}$ peso da massa seca da parte aérea das plantas de tiririca que se desenvolveram no solo com $30 \%$ da C.S. e sem aplicação do herbicida foi menor do que o das plantas que se desenvolveram no solo com 60 e $100 \%$ da C.S.

Pelos resultados apresentados, pode-se inferir que a re-hidratação das plantas de tiririca 24 horas após a aplicação do halosulfuron elimina os efeitos de 10 dias de diferentes níveis de estresse hídrico, até mesmo quando a planta foi submetida a $\psi_{\mathrm{w}} \geq-2,6 \mathrm{MPa}$, permitindo que o herbicida manifestasse todo o seu potencial de controle dessa planta daninha, reduzindo em $43 \%$ a brotação, em $45 \%$ a massa da matéria seca dos tubérculos, em $87 \%$ a altura das plantas e em $96 \%$ a massa da matéria seca da parte aérea.

Quando a re-hidratação ocorreu 48 horas após a aplicação do herbicida já houve efeito do histórico do estresse hídrico da planta, que se manifestou pelo efeito interativo dos fatores: capacidade de saturação do solo e aplicação do herbicida. Por essa interação pode-se constatar que quando a planta de tiririca se encontrava sob estresse de $\psi_{\mathrm{w}}>-2,6 \mathrm{MPa}$, que correspondeu a $30 \%$ da capacidade de saturação do solo, a aplicação do halosulfuron, embora tenha reduzido a altura da parte aérea e a massa da matéria seca dessa, não logrou em reduzir o número de brotações por tubérculos, demonstrando baixa translocação do produto. O herbicida se mostrou mais eficaz no controle da tiririca quando aplicado na planta com $\psi_{\mathrm{w}}=-0,2$ a $-0,4 \mathrm{MPa}$, ou seja, quando o solo se encontrava com $60 \%$ de sua capacidade de saturação, superando o controle observado nos solos com saturação de 45 e 100\%, principalmente quanto à brotação do tubérculo. 
TABELA 4. Altura e número de brotações e massa da matéria seca de tubérculos e da parte aérea de tiririca, quando submetida a diferentes níveis de capacidade de saturação do solo e a aplicação ou não de halosulfuron. Jaboticabal, SP (corte 48 h após a aplicação).

\begin{tabular}{|c|c|c|c|c|c|c|c|c|}
\hline \multirow{2}{*}{$\begin{array}{c}\text { Capacidade de } \\
\text { Saturação do solo }\end{array}$} & \multicolumn{3}{|c|}{ Altura das brotações $(\mathrm{cm})$} & \multicolumn{3}{|c|}{ Número de brotações ${ }^{1 .}$} & \multicolumn{2}{|c|}{ Matéria seca (g) } \\
\hline & $7 \mathrm{DAC}^{3}$ & $21 \mathrm{DAC}$ & $28 \mathrm{DAC}$ & $7 \mathrm{DAC}$ & $21 \mathrm{DAC}$ & $28 \mathrm{DAC}$ & Tubérculos & Parte aérea \\
\hline 30 & $3,25 \mathrm{~A}^{2}$ & $5,25 \mathrm{~A}$ & $5,25 \mathrm{~A}$ & $2,52 \mathrm{~A}$ & $2,34 \mathrm{~A}$ & $2,53 \mathrm{~A}$ & $1,79 \mathrm{~A}$ & $0,33^{\mathrm{A}}$ \\
\hline 45 & $2,81 \mathrm{~A}$ & $4,11 \mathrm{~A}$ & $4,61 \mathrm{~A}$ & $2,22 \mathrm{AB}$ & $1,97 \mathrm{AB}$ & $1,88 \mathrm{~B}$ & $1,93 \mathrm{~A}$ & $0,35^{\mathrm{A}}$ \\
\hline 60 & $3,20 \mathrm{~A}$ & $4,00 \mathrm{~A}$ & $4,33 \mathrm{~A}$ & $2,32 \mathrm{AB}$ & $1,43 \mathrm{~B}$ & $1,40 \mathrm{~B}$ & $1,87 \mathrm{~A}$ & $0,35^{\mathrm{A}}$ \\
\hline 100 & $2,59 \mathrm{~A}$ & $4,61 \mathrm{~A}$ & $4,86 \mathrm{~A}$ & $2,12 \mathrm{~B}$ & $1,82 \mathrm{AB}$ & $1,77 \mathrm{~B}$ & $1,42 \mathrm{~A}$ & $0,38 \mathrm{~A}$ \\
\hline \multicolumn{9}{|l|}{ Herbicida } \\
\hline $\mathrm{COM}$ & $0,70 \mathrm{~B}$ & $0,99 \mathrm{~B}$ & $0,99 \mathrm{~B}$ & $2,00 \mathrm{~B}$ & $1,07 \mathrm{~B}$ & $1,03 \mathrm{~B}$ & $1,18 \mathrm{~B}$ & $0,04 \mathrm{~B}$ \\
\hline SEM & $4,43 \mathrm{~A}$ & $8,00 \mathrm{~A}$ & $8,54 \mathrm{~A}$ & $2,59 \mathrm{~A}$ & $2,71 \mathrm{~A}$ & $2,76 \mathrm{~A}$ & $2,33 \mathrm{~A}$ & $0,66 \mathrm{~A}$ \\
\hline F cap. sat.(C) & $17,61 \mathrm{NS}$ & $3,19 \mathrm{NS}$ & $1,39 \mathrm{NS}$ & $3,64 *$ & $4,23 *$ & $9,26 * *$ & $0,82 \mathrm{NS}$ & $1,13 \mathrm{NS}$ \\
\hline F herb. $(\mathrm{H})$ & $218,39 * *$ & $483,44 * *$ & $525,16 * *$ & $43,29 * *$ & $82,45 * *$ & $124,73 * *$ & $20,79 * *$ & $856,17 * *$ \\
\hline $\mathrm{C} \times \mathrm{H}$ & $16,01 * *$ & $3,19 \mathrm{NS}$ & $4,61 *$ & $13,22 * *$ & $10,37 * *$ & $12,81 * *$ & $2,44 \mathrm{NS}$ & $5,45^{* *}$ \\
\hline $\mathrm{CV}(\%)$ & 24,09 & 17,36 & 16,93 & 9,48 & 23,44 & 19,88 & 35,15 & 14,55 \\
\hline DMS (C) & 1,02 & 1,29 & 1,33 & 0,36 & 0,73 & 0,62 & 1,02 & 0,08 \\
\hline $\operatorname{DMS}(\mathrm{H})$ & 0,53 & 0,67 & 0,69 & 0,18 & 0,38 & 0,32 & 0,53 & 0,04 \\
\hline
\end{tabular}

${ }^{1}$ Dados transformados para $\sqrt{\left(n^{\circ}\right)}$.

2 Medias seguidas por mesma letra não diferem entre si a $5 \%$ de probabilidade pelo teste de Tukey

${ }^{3} \mathrm{AC}=$ dias após o corte da parte aérea 
TABELA 5. Efeito da interação da capacidade de saturação (CS) de água no solo com aplicação do halosulfuron sobre a altura e número de brotações e massa da matéria seca da parte aérea de tiririca. Jaboticabal, SP, 1996.

\begin{tabular}{|c|c|c|c|c|c|c|c|c|c|c|}
\hline \multirow{3}{*}{ C.S. $(\%)$} & \multirow{2}{*}{\multicolumn{2}{|c|}{$\begin{array}{l}\text { altura média } \\
(\mathrm{cm})\end{array}$}} & \multicolumn{6}{|c|}{ Número de brotações ${ }^{1 .}$} & \multirow{2}{*}{\multicolumn{2}{|c|}{$\begin{array}{c}\text { Matéria seca } \\
\text { Parte aérea (g) }\end{array}$}} \\
\hline & & & & $C^{3 .}$ & 211 & & 281 & & & \\
\hline & s/ herb & $\mathrm{c} /$ herb & s/ herb & $\mathrm{c} /$ herb & s/ herb & $\mathrm{c} /$ herb & s/ herb & $\mathrm{c} /$ herb & s/ herb & $\mathrm{c} /$ herb \\
\hline 30 & $8,00 \mathrm{Aa}^{2}$ & $2,50 \mathrm{Ba}$ & $2,44 \mathrm{Aa}$ & $2,60 \mathrm{Aa}$ & $2,37 \mathrm{Aa}$ & $2,30 \mathrm{Aa}$ & $2,64 \mathrm{Aa}$ & $2,42 \mathrm{Aa}$ & $0,57 \mathrm{Ab}$ & $0,09 \mathrm{Ba}$ \\
\hline 45 & $8,50 \mathrm{Aa}$ & $0,73 \mathrm{Bab}$ & $2,45 \mathrm{Aa}$ & $2,00 \mathrm{Bb}$ & 2,97Aa & $0,98 \mathrm{Bb}$ & 2,97Aa & $0,80 \mathrm{Bbc}$ & $0,69 \mathrm{Aab}$ & $0,26 \mathrm{Ba}$ \\
\hline 60 & $8,66 \mathrm{Aa}$ & $0,00 \mathrm{Bb}$ & 2,64Aa & $2,00 \mathrm{Bb}$ & $2,87 \mathrm{Aa}$ & $0,00 \mathrm{Bb}$ & $2,81 \mathrm{Aa}$ & $0,00 \mathrm{Bc}$ & 0,70Aa & $0,00 \mathrm{Ba}$ \\
\hline 100 & $9,00 \mathrm{Aa}$ & $0,73 \mathrm{Bab}$ & $2,83 \mathrm{Aa}$ & $1,41 \mathrm{Bc}$ & $2,64 \mathrm{Aa}$ & $1,00 \mathrm{Bb}$ & $2,62 \mathrm{Aa}$ & $0,92 \mathrm{Bb}$ & $0,71 \mathrm{Aa}$ & $0,06 \mathrm{Ba}$ \\
\hline
\end{tabular}

Moosavi-nia \& Dore (1979) sujeitaram plantas adultas de tiririca ao desenvolvimento sob três níveis de umidade de solo: próximo a capacidade de campo e estresses moderado e severo. O aumento do estresse resultou em partes aéreas menores e em menor número e reduziu o número, tamanho e massa dos tubérculos. Após o tratamento com glyphosate, as plantas foram mantidas sob mesmo regime de umidade do solo, a parte aérea foi cortada uma semana após e a brotação foi avaliada após seis semanas. Os autores verificaram que o desempenho do glyphosate foi reduzido com o aumento do estresse. Entretanto, o retorno das plantas estressadas para as condições de capacidade de campo do solo por uma semana antes ou após a aplicação fez com que o controle obtido se assemelhasse ao das plantas mantidas continuamente na capacidade de campo. Segundo os autores, isso sugere que a redução na eficiência do glyphosate em plantas estressadas pode ser atribuída primariamente a processos fisiológicos e bioquímicos, que normalizam com a remoção de estresse, do que a mudanças irreversíveis no crescimento como tamanho e forma das folhas e deposição de cera cuticular.

Chase \& Appleby (1979) reduziram a aplicação de água para tiririca por 4 a 5 dias antes do tratamento com glyphosate, mantendo este regime hídrico até a avaliação. As partes aéreas foram cortadas 24 horas após a pulverização e a brotação foi avaliada após 2 e 4 dias. Um potencial hídrico da planta de $-0,8$ MPa não reduziu a eficiência do glyphosate, mas a $-1,1 \mathrm{MPa}$ o controle obtido foi metade do observado nas plantas sob capacidade de campo. A translocação do ${ }^{14} \mathrm{C}$-glyphosate para o sistema subterrâneo 24 horas após a aplicação sob $-1,1$ MPa foi metade do observado a -0,2 MPa.

McWhorter et al. (1980) verificaram que a absorção e translocação do ${ }^{14} \mathrm{C}$-glyphosate após 72 horas da aplicação em Sorghum halepense e soja não foram afetadas pela umidade do solo quando a umidade e a temperatura do ar eram de $100 \%$ e $24^{\circ} \mathrm{C}$. Entretanto, altas temperaturas e baixas umidades combinadas com a umidade do solo chegando ao ponto de murchamento reduziram significativamente a absorção e translocação do ${ }^{14} \mathrm{C}$-glyphosate nas duas espécies. Segundo os autores, esses resultados indicam que o estresse hídrico na planta pode reduzir a penetração do glyphosate num intervalo de 72 horas e que, de alguma forma, uma alta umidade relativa do ar pode compensar a baixa umidade do solo. Neste trabalho, no decorrer dos 28 dias após a aplicação do halosulfuron, a umidade relativa foi de 78,0\% \pm 4,6 e as temperaturas mínima e máxima do ar foram de $20,2^{\circ} \mathrm{C} \pm 0,8$ e $31,5^{\circ} \mathrm{C} \pm 0,9$, respectivamente, condições essas que podem ter contribuído para os resultados obtidos com os solos em baixa capacidade de saturação. 


\section{LITERATURA CITADA}

ASALEY, J.C. \& COUPLAND, D. Environmental and plant factors affecting glyphosate uptake, movement and activity. In: The herbicide glyphosate. GROSSBARD, E. \& ATKINSON, D. (ED.) London, Butter Worths. p. 92-123. 1985.

CHASE, R. L. \& APPLEBY, A. P. Effects of humidity and moisture stress on glyphosate control of Cyperus rotundus L. Weed Res., v. 19, p. 241-246, 1979.

ERASMO, E.L.A.; ALVES, P.L.C.A. KUVA, M.A. Fatores que afetam a brotação de tubérculos de tiririca (Cyperus rotundus L.): I. Qualidade da luz, concentração de $\mathrm{CO}_{2}$ e temperatura. Cult. Agron., v. 3, n. 1, p. 5566, 1994.

HARVEY, B. M. R. \& CROTHERS, S. H. Effects of water stress on uptake and efficacy of glyphosate. Ann. Appl. Biol., v. 113, n. 1, p 61-68, 1988.

HAY, J. R. Herbicide transport in plants. In: Herbicides. AUDUS, L. J. (ED), London, Academic Press, $2^{a}$ Ed., vol. 1, p 365-396, 1976.

HAZARD, W.H.L., PALU, L.M. Nutgrass and treatment. Queens. Agric. J., v.11, p.219226, 1986.

HOLM, L.G., PLUNCKNETT, D.L. PANCHO, J.V., HERBERGER, J.P. The world's worst weeds. Honnolulu: University Press of Hawaii, p. 8-24. 1977.

KUVA, M.A.; ALVES, P.L.C.A.; ERASMO, E.L.A. Efeitos da solarização do solo com plástico transparente sobre $\mathrm{o}$ desenvolvimento da tiririca (Cyperus rotundus). Planta Daninha, v. 13, n. 1, p. 26-31, 1995 a.

KUVA, M.A.; ALVES, P.L.C.A. \& ERASMO, E.L.A. Efeitos da solarização do solo com plástico transparente sobre $\mathrm{o}$ desenvolvimento de tiririca (Cyperus rotundus L.) em condições de outonoinverno. Científica v. 23, n. 2, p. 331-341, 1995 b.

LEVIT, J. Responses of plants to environmental stress, $2^{\mathrm{a}}$ ed, vol. 1, London, Academic Press, 560 p. 1980.

MAGALHÃES, A.C. Influência do teor de umidade no tubérculo e da quantidade de água disponível no solo sobre a capacidade de brotação da tiririca. Bragantia, v.24, p.507-523, 1965.

McWHORTER, C. G., JORDAN, T. N., WILLS, G. D. Translocation of ${ }^{14} \mathrm{C}$ glyphosate in soibean (Glycine max) and Johnson grass (Sorghun halepense). Weed Sci., v.28, p. 113-118, 1980.

MOOSAVI-NIA, H. \& DORE, J. Factors affecting glyphosate activiy in Imperata Cylindrica (L) Beau and Cyperus rotundus L. I. Effects of soil moisture. Weed Res., v.19, p. 321327, 1979.

NEMOTO, M.C.M.; NEMOTO, L.R.P.; ALVES, P.L.C.A., PITELLI, R.A.; DAMIÃO FILHO, C.F. Efeitos do sombreamento e da adubação fosfatada sobre aspectos biológicos da tiririca (Cyperus rotundus L.). Cult. Agron., v. 3, n 1, p. 129-144, 1994.

NEMOTO, M.C.M.; ALVES, P.L.C.A.; PITELLI, R.A.; NEMOTO, L.R.P. Comportamento da tiririca (Cyperus rotundus) sob diferentes níveis de adubação fosfatada e de sombreamento. Planta Daninha, v. 13, n. 1, p. 50-55, 1995. 
RAHMAN, A.; JAMES, T. K. Influence of soil moisture on the post emergence activity of nine sulfonylurea herbicides. Proceedings, Asian Pacific Weed Society Conference. n 1, p 331-337. 1991.

STOLLER, E.W., SWEET, D.R. Biology and life cicle of purple and yellow nutsedge (Cyperus rotundus and C. esculentus). Weed Technol., v.1, n.1, p.66-73, 1987.

WALIA, U.S.; GILL, H. S. Influence of variable levels of soil moisture and spray volume on the bioefficacy of substituted urea herbicides for control of Phalaris minor Rets in wheat. J. Res., v. 22, n. 3, p 443448, 1985.

WINTER, E.J. A água, o solo e a planta. EDUSP. São Paulo. 1976. 169p.

ZHANG, C.X. \& PRICE, C.E. Effects os salinity and soil moisture stresses on the uptake, translocation \& biological activity of glyphoste in Echinochloa crus-galli (L.) Beauv. Proceedings, Brighton Crop Protection Conference. v.2, p. 641-642, 1993. 